\title{
Imaturos de Sarsina violascens (Herrich-Schäffer) (Lepidoptera, Noctuidae, Lymantriinae)
}

\author{
Marina Moraes C. ${ }^{1}$, Luis Anderson Ribeiro Leite ${ }^{1}$, Mirna Martins Casagrande ${ }^{1} \&$ Olaf Hermann Hendrik Mielke \\ 'Departamento de Zoologia, Universidade Federal do Paraná, Caixa Postal 19020, 81531-980 Curitiba-PR, Brasil. marimoraesca@gmail.com, madison.2@ \\ ig.com.br, mibras@ufpr.br,omhesp@ufpr.br
}

\begin{abstract}
Immatures of Sarsina violascens (Herrich-Schäffer) (Lepidoptera, Noctuidae, Lymantriinae). Sarsina violascens is a polyphagous species that also feeds on $P$. cattleianum Sabine (Myrtaceae) during the larval stages. In this study the morphology and the behaviour of the immature stages of this species are described and illustrated, including scanning electronic microscopy photographs.
\end{abstract}

KEYWORDS. Bionomy; life cycle; Neotropical; Noctuoidea.

RESUMO. Imaturos de Sarsina violascens (Herrich-Schäffer) (Lepidoptera, Noctuidae, Lymantriinae). Sarsina violascens é uma espécie polífaga que eventualmente se alimenta de P. cattleianum Sabine (Myrtaceae) durante sua fase larval. Neste estudo são descritas a morfologia e o comportamento dos imaturos, com ilustrações, fotografias e imagens de microscopia eletrônica de varredura.

PALAVRAS-CHAVE. Bionomia; ciclo de vida; Neotropical; Noctuoidea.

Recentemente, os lepidópteros amplamente reconhecidos como representantes de Lymantriidae foram reclassificados e, no novo arranjo taxonômico, incluídos como uma subfamília de Noctuidae. Seus representantes encontram-se agrupados em um clado formado pelos noctuídeos que se caracterizam por apresentar capuz timpânico pré-espiracular, filogeneticamente próximos de Arctiinae e Nolinae, anteriormente também reconhecidos como famílias (Lafontaine \& Fibiger 2006).

Os representantes de Lymantriinae geralmente são mariposas de tamanho médio, com cerca de 2700 espécies conhecidas, presentes em todos os continentes. Suas larvas, polífagas e arbóreas, muitas vezes são desfolhadoras de grandes áreas florestais (Scoble 1992). Algumas espécies apresentam variados mecanismos de defesa contra predadores, como cerdas tóxicas, glândulas eversíveis ou mesmo a capacidade de construírem abrigos coletivos de seda formando tendas (Costa 2006).

Sarsina violascens (Herrich-Schäffer, 1856) apresenta larvas polífagas que eventualmente se alimentam de folhas de P. cattleianum Sabine (Myrtaceae). Possui potencial econômico devido ao seu status de praga em Eucalyptus spp. (Myrtaceae) (Zanuncio \& Lima 1975; Zanuncio et al. 1992).

Psidium cattleianum Sabine ou araçazeiro é uma das 70 espécies de Psidium (Souza \& Sobral 2007), originária e cultivada no Brasil. Foi introduzida a partir do século XVIII como planta ornamental e frutífera em diferentes regiões do mundo (Marques et al. 2007). Estudos desenvolvidos com a entomofauna associada à $P$. cattleianum revelam que alguns lepidópteros a utilizam como planta hospedeira (Wilker \& Vitorino 2007), entretanto as espécies não foram identificadas, ilustradas ou descritas.
Segundo Dias (2006), muitas espécies de Lepidoptera possuem poucas informações sobre imaturos, sendo a maioria completamente desconhecidos ou com descrições apenas do último ínstar larval, da pupa e alguns dados sobre a planta hospedeira, gerando um vasto campo de estudo aos taxônomos.

O propósito deste estudo é evidenciar aspectos morfológicos, da história natural e possibilitar comparações com imaturos de outras subfamílias de Noctuidae, especialmente aquelas mais próximas filogeneticamente.

\section{MATERIAL E MÉTODOS}

Ovos de S. violascens foram coletados sobre ramos de P. cattleianum, em Curitiba, Paraná, Brasil, mantidos em recipiente plástico e borrifados com água mineral diariamente para a manutenção da umidade. Após a eclosão, as larvas de primeiro ínstar foram transferidas para gaiolas de criação juntamente com a planta hospedeira. A troca dos galhos e a limpeza das gaiolas foram realizadas diariamente.

Larvas foram sacrificadas em água fervente em um número mínimo de duas por ínstar e posteriormente fixadas em líquido Kahle-Dietrich 10\% (Borror \& DeLong 1971) por um período de três dias, sendo então transferidas para álcool $70 \%$. As cápsulas cefálicas, mantidas a seco, foram coletadas e conservadas a cada mudança de ínstar.

Os indivíduos foram observados periodicamente, descritos e fotografados com o auxílio de câmera digital LEICA ${ }^{\circledR}$ MZ16 e software Syncroscopy ${ }^{\circledR}$ Auto-montage Pro ${ }^{\circledR}$ versão 5.03.0040. Detalhes de estruturas foram feitas em microscopia eletrônica de varredura. Para estudos de 
quetotaxia, as estruturas foram desenhadas com auxílio de microscópio estereoscópico acoplado à câmara clara e lente micrométrica para as medições. A terminologia aplicada às estruturas das larvas e pupas foi principalmente a de Dias (2006). Adaptações foram feitas, a partir de outros trabalhos que abordam aspectos morfológicos dos imaturos (Mosher 1916; Peterson 1962; Stehr 1987; Scoble 1992; Zenker et al. 2007; Rougerie \& Estradel 2008).

\section{RESULTADOS}

\section{Ovo}

(Figs. 3-5, 23)

Esférico, liso e com pólo inferior plano. Logo após a oviposição a coloração é creme uniforme com linha alaranjada que o circunda medianamente. Área micropilar arredondada e alaranjada, evidente no pólo superior. Próximo à eclosão torna-se acinzentado com pequenas manchas cinza-escuras, esbranquiçadas e castanhas que se distribuem irregularmente no seu interior e visíveis externamente pela transparência do cório. Diâmetro médio: 1,24mm (n=29). Duração mínima: 13 dias.

Larva de $1^{\circ}$ ínstar

(Figs. 6, 18, 19)

Cabeça arredondada, amarelo-olivácea com cerdas e sem escolos. Fronte dividida pela sutura epicranial, lateralmente a esta o epicrânio ocupa a maior porção da cabeça, onde também estão a maioria das cerdas primárias. Fronte de aspecto triangular, localizada na metade inferior da cabeça, delimitada lateralmente pela sutura epicranial e inferiormente pelo clípeo, este tem o formato de uma banda esclerotinizada transversal, estreito medianamente e pouco mais largo em direção às extremidades. Anteclípeo membranoso. Labro bilobado. Seis estemas látero-ventralmente dispostos em semicírculo, estemas 3, 4 e 5 maiores, os demais menores e semelhantes. Antena com três artículos, sendo o basal mais largo e comprido, o mediano o mais curto e o distal pouco projetado e com cerdas na extremidade.

Placa pronotal castanho-clara, subretangular com inúmeras cerdas dispostas na porção anterior, em duas projeções tegumentares afastadas entre si na linha média dorsal. Pernas torácicas semelhantes, com tarso uniarticulado e garra terminal.

Tegumento do restante do corpo castanho-claro. Dorso com inúmeras cerdas distribuídas desde o primeiro segmento torácico até o nono segmento abdominal em um par de projeções tegumentares, dorso-laterais, como aquelas do pronoto. Cerdas laterais, distribuídas em todos os segmentos torácicos e abdominais sobre verrugas, uma maior e outra menor por segmento, superior e inferior respectivamente, sendo as laterais de $\mathrm{T} 1$ as maiores e projetadas em direção à cabeça.

Pernas abdominais de A3 - A6 e do último segmento com ganchos dispostos em mesosérie uniordinal, esta conformação se repete nos ínstares posteriores. Desde o primeiro até o último ínstar, as pernas de A3 - A6 permanecem estendidas lateralmente diferentemente de outros grupos onde as mesmas se posicionam ventralmente.

Apesar de os ovos serem depositados em grupos, já no primeiro ínstar as larvas apresentam comportamento solitário, alimentando-se de forma independente encontrando-se nos galhos ou nas folhas da planta hospedeira.

A alimentação é diurna, com pequenos movimentos semicirculares na borda e seguindo em direção à nervura principal da folha, não havendo o consumo desta por completo.

Mensurações: $(\mathrm{n}=10)$. Cápsula cefálica: largura $-0,75 \mathrm{~mm}$; altura $-0,66 \mathrm{~mm}$. Comprimento médio da larva antes da muda: 4,6mm. Duração mínima: 10 dias.

\section{Quetotaxia da Cabeça \\ (Figs. 18, 19)}

Dezoito pares de cerdas primárias, excluindo as cerdas do labro. Grupo Clipeal (C): C2 próxima à linha mediana sagital da cabeça; $\mathrm{C} 1$ com o mesmo comprimento de $\mathrm{C} 2$ e próxima da margem lateral do clípeo. Grupo Frontal (F): F1 é a única cerda da fronte e próxima à sutura epicranial; poro $\mathrm{Fa}$ ventral a $\mathrm{F} 1$ e próximo da linha média sagital. Grupo Adfrontal (Af): Af1 e Af2 com o mesmo comprimento; poro Afa ausente. Grupo Anterior $(\mathrm{A})$ : $\mathrm{A} 1$ próxima à margem inferior do epicrânio na altura do clípeo; A2 dorsal à A1 e situada medianamente entre a região estemal e a fronte; $\mathrm{A} 3$ látero-dorsal à região estemal; poro Aa não observado. Grupo Estemal (E): E1 lateral ao estema 3; E2 látero-dorsal ao estema 1 na margem lateral do epicrânio; E3 lateral ao semicírculo estemal e próxima à margem ínfero-posterior do epicrânio; poros Ea e Eb não observados. Grupo Subestemal (Se): Se3 ventral ao estema 6. Demais cerdas subestemais não observadas. Grupo Microgenal (Mg): Mg1 na extremidade ínfero-posterior do epicrânio; poro Mga látero-dorsal à Mg1. Grupo Lateral (L): L1 látero-dorsal à E2; poro La não observado.

Grupo Póstero-dorsal (P): P1 entre L1 e a sutura epicranial; $\mathrm{P} 2$ dorsal à $\mathrm{P} 1$; poro $\mathrm{Pa}$ látero-ventral à $\mathrm{P} 1$ e poro $\mathrm{Pb}$ látero-dorsal à $\mathrm{P} 1$. Grupo de Microcerdas dorsais $(\mathrm{Md})$ : Md2 na extremidade dorsal da cabeça; Md3 látero-ventral a $\mathrm{Md} 2$ e de comprimento maior que estas; $\mathrm{Md} 1$ e poro Mda não observados.

\section{Larva de $2^{\circ}$ ínstar}

(Fig. 7)

Cabeça predominantemente amarelo-escura, sendo as regiões estemal e apical das mandíbulas castanhas. Placa pronotal com tonalidade similar à cabeça, mas com bordas laterais enegrecidas. Segmentos torácicos e de A1 - A7 amarelo-translúcidos com estreitas faixas dorsais enegrecidas na base dos escolos T2 - A7 e A8 - A10 amarelo-claro.

Mensurações: $(\mathrm{n}=5)$. Cápsula cefálica: largura $-0,97 \mathrm{~mm}$; altura $-0,86 \mathrm{~mm}$. Comprimento médio da larva antes da muda: 5,94mm. Duração mínima: 10 dias. 

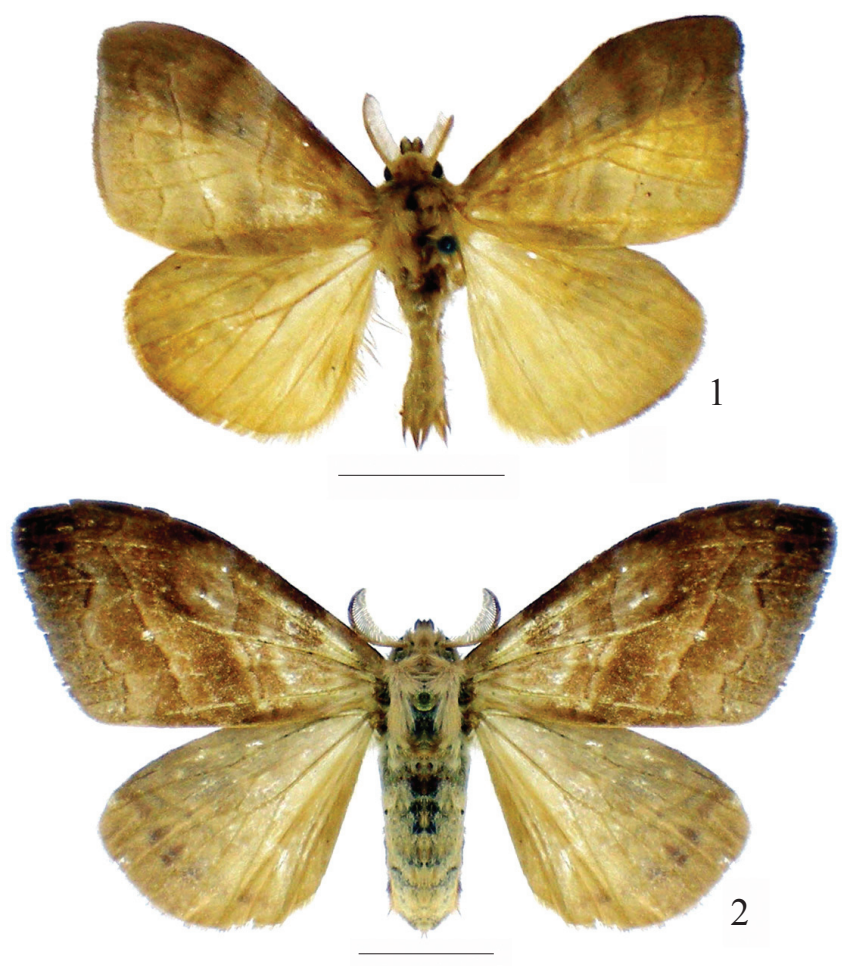

Figs. 1-2. Sarsina violascens. 1, Macho vista dorsal; 2, Fêmea vista dorsal.

Larva de $3^{\circ}$ ínstar

(Figs. 8, 12, 28)

Cabeça amarelo-clara; placa pronotal amarelo-oliva com bordas laterais castanhas; escolo látero-superior do protórax com ápice castanho-escuro e longas cerdas escurecidas, demais cerdas do corpo esbranquiçadas, exceto algumas na região dorsal de A10 que são enegrecidas. Cerdas mais longas lateralmente e curtas no dorso em todos os segmentos. Tegumento do corpo de T1 - A7 amarelo-oliva translúcido e de A8- A10 amarelo-oliva menos intenso. Estreitas faixas de manchas enegrecidas nos escolos dorsais de T3 - A9; em T2 estas manchas são arredondadas e em A4 maiores que as de T2 e subtriangulares. Glândulas circulares amareladas dispostas na linha mediana dorsal de A1 - A7, sendo as pertencentes aos segmentos A6 e A7 maiores em relação às demais.

Mensurações: $(\mathrm{n}=5)$. Cápsula cefálica: largura - 1,63mm; altura $-1,47 \mathrm{~mm}$. Comprimento médio da larva antes da muda: 12,35mm. Duração mínima: 15 dias.

\section{Larva de $4^{\circ}$ ínstar}

(Figs. 9 e 13)

Semelhante ao ínstar anterior, exceto pela presença de faixa de um amarelo intenso que percorre a larva dorsalmente desde a região posterior do protórax até a margem posterior de A9.

Mensurações: $(\mathrm{n}=5)$. Cápsula cefálica: largura - 2,05mm; altura $-1,87 \mathrm{~mm}$. Comprimento médio da larva antes da muda: 16,47mm. Duração mínima: 12 dias.
Larva de $5^{\circ}$ ínstar

(Figs. 10, 29, 30)

Cabeça amarelo-esverdeada com duas manchas negras em forma de vírgula no epicrânio na altura das cerdas póstero-dorsais. Tegumento do restante do corpo verdeoliva, com a região dorsal mais escurecida. Longas cerdas escurecidas localizadas lateralmente em T1 e de A1 - A10, restante das cerdas esbranquiçadas e com cerca de dois terços do comprimento das cerdas escuras. Manchas pertencentes aos escolos dorsais mais escuras em relação aos ínstares anteriores e glândulas mediano-dorsais mais conspícuas.

Mensurações: $(n=5)$. Cápsula cefálica: largura $-2,75 \mathrm{~mm}$; altura $-2,45 \mathrm{~mm}$. Comprimento médio da larva antes da muda: 23,52mm. Duração mínima: 13 dias.

Larva de $6^{\circ}$ ínstar

(Figs. 11, 24-27)

Cabeça verde-oliva com formato semelhante ao ínstar anterior. Tegumento do corpo também verde-oliva com regiões intersegmentais amarelo-esverdeadas. Manchas castanhoclaras dispostas dorsalmente em T1 e T2. T3 com mancha dorsal enegrecida na metade anterior. Manchas enegrecidas na base dos escolos dorsais no restante do corpo, mais conspícuas em A4 e A6. Espiráculos abdominais elípticos e ântero-ventrais aos escolos laterais superiores.

Mensurações: $(n=5)$. Cápsula cefálica: largura $-4,05 \mathrm{~mm}$; altura $-3,78 \mathrm{~mm}$. Comprimento médio da larva antes da muda: $30 \mathrm{~mm}$. Duração mínima: 18 dias.

Ao final deste ínstar, as larvas escolhem um local apropriado para empupar. Tecem seda entre as folhas, formando uma teia na qual permanecem com um aspecto de "U" curvadas ventralmente com a cabeça voltada em direção ao último segmento abdominal. Neste período os indivíduos não ficam em contato com as folhas ou galhos, mas apenas suspensos pela teia de seda. Período pré-pupal $(n=5)$ de 1 dia.

$$
\text { Pupa }
$$

(Figs. 14-17, 20-22, 31-32)

Obtecta, suspensa pela teia de seda confeccionada em meio às folhas. Alargada na altura de A2 e A3 e diminuindo gradativamente de largura em direção ao cremaster. Tegumento fino com inúmeras cerdas amareladas distribuídas de forma irregular nos segmentos torácicos e abdominais, sendo mais abundantes a partir de A8. Inicialmente de coloração verdeoliva e após um período mínimo de vinte e quatro horas passa a uma tonalidade castanho-clara com vértice, fronte e áreas das asas em coloração castanho-escuras.

Cabeça levemente achatada ventralmente, com aspecto rugoso; clípeo subquadrangular; fóveas tentoriais anteriores laterais ao clípeo; região das mandíbulas arredondada ventrolateralmente ao clípeo; palpos labiais curtos e abaixo do labro; gáleas ventrais às mandíbulas, junto ao labro, e com cerca da metade do comprimento das pernas protorácicas; olhos 

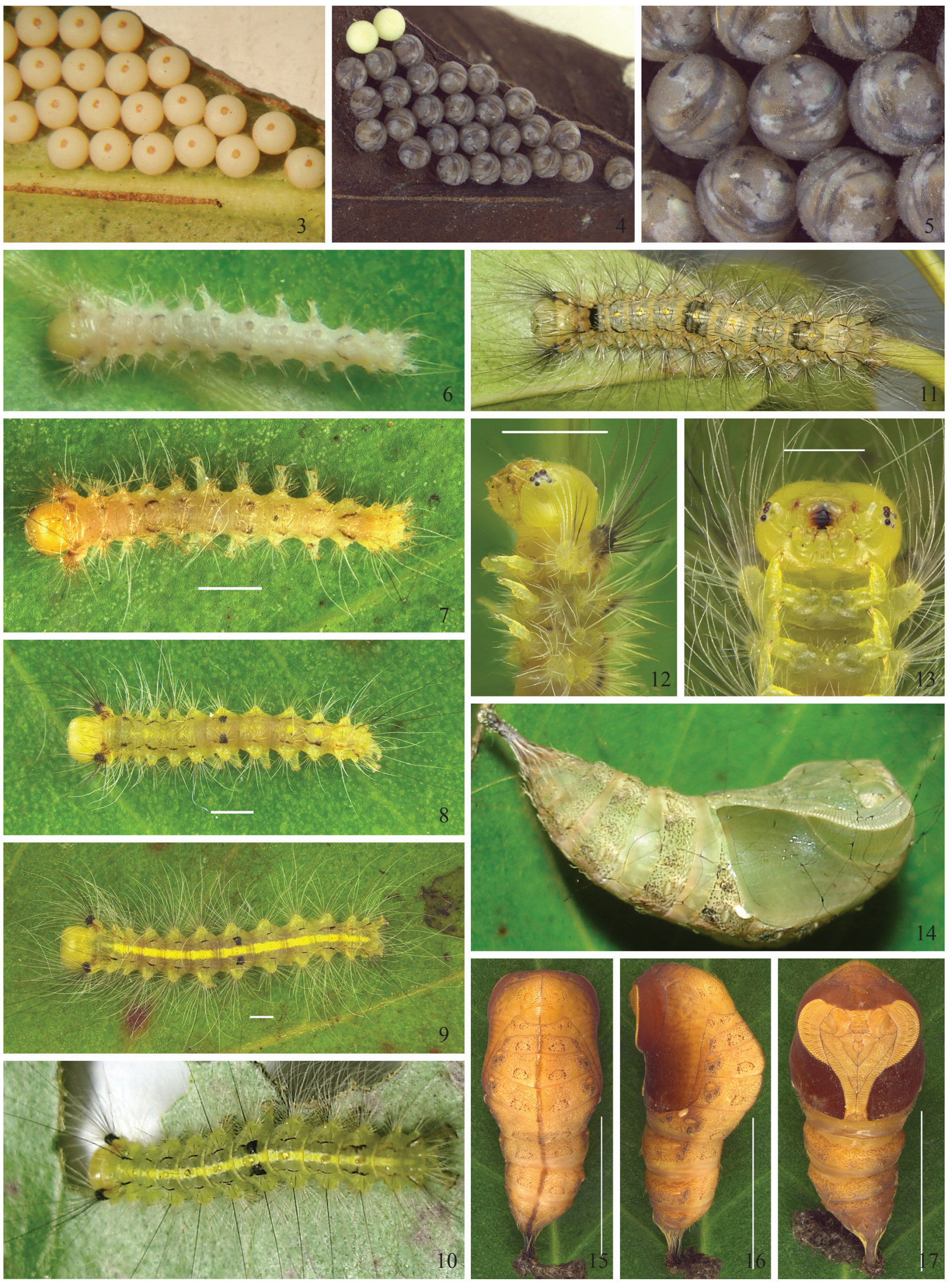

Figs. 3-17. Sarsina violascens. 3-5, postura: 4-5, postura, pré-eclosão; 6-13, larvas: 6, $1^{\circ}$ ínstar; 7, $2^{\circ}$ ínstar; 8, $3^{\circ}$ ínstar; $9,4^{\circ}$ ínstar; $10,5^{\circ}$ ínstar; $11,6^{\circ}$ ínstar; $12,3^{\circ}$ ínstar vista lateral da cabeça e segmentos torácicos; $13,4^{\circ}$ ínstar vista ventral da cabeça e segmentos torácicos. 14-17, Pupa: 14, pupa recém formada na teia de sustentação; 15-17, pupa após vinte e quatro horas da formação: 15, vista dorsal; 16, vista lateral; 17, vista ventral. 


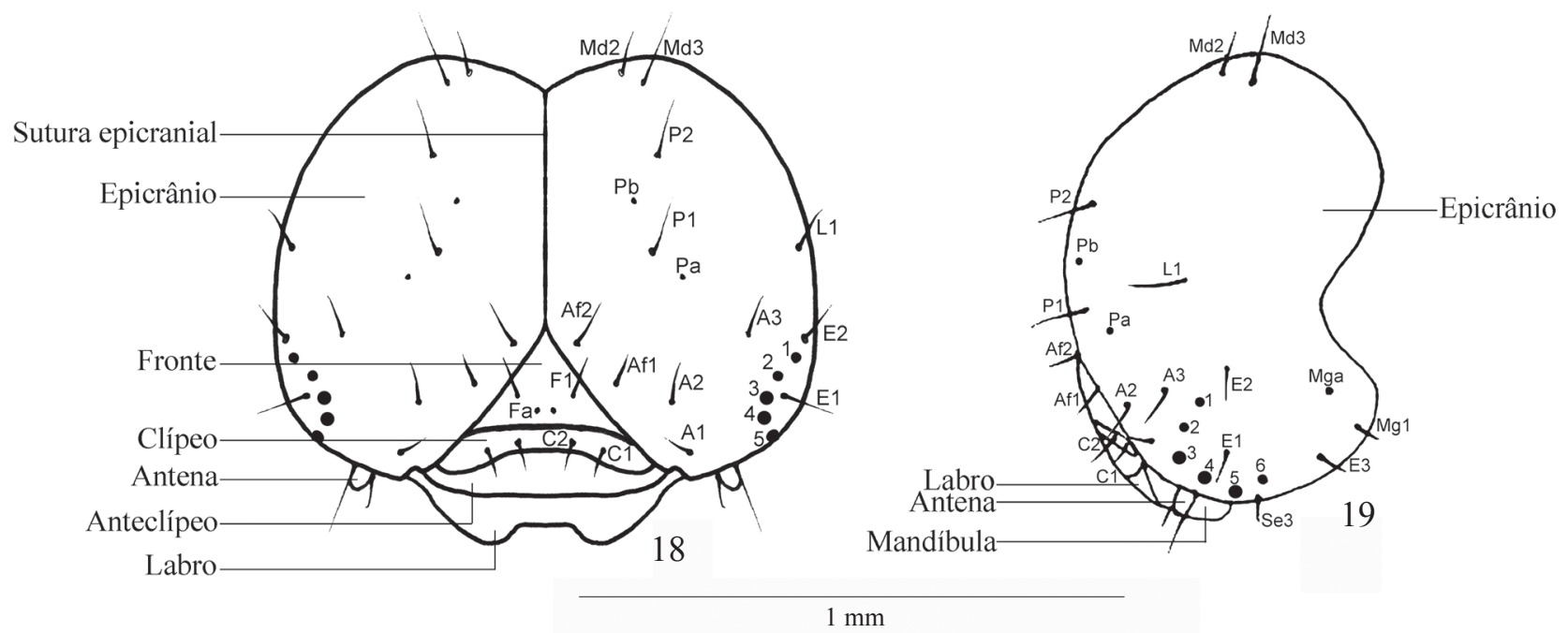

Figs. 18-19. Sarsina violascens. Quetotaxia da cabeça - larva de $1^{\circ}$ ínstar. 18, vista frontal; 19, vista lateral.

compostos ovais, localizados lateralmente às mandíbulas. Antenas largas, de aspecto estriado, laterais aos olhos e terminando junto ao terço anterior das pernas mesotorácicas.

Pronoto subretangular e de coloração mais escura em relação aos demais segmentos do tórax. Mesonoto, o maior dentre os três segmentos, escurecido em direção as asas. Metatórax pequeno e com margem ântero-mediana convexa. Dorso de todos os segmentos torácicos com uma estreita linha longitudinal escurecida, com pontuações escuras distribuídas de forma irregular dorso-laterais à linha longitudinal.

Pernas protorácicas laterais às gáleas; mesotorácicas junto ao terço inferior das antenas e terminando sobre a extremidade distal das metatorácicas, estas terminando junto ao ápice das asas posteriores.

Abdome com dez segmentos, lateralmente com espiráculos elípticos de A2 - A8, sendo os de A8 menores. Dorso de todos os segmentos com uma faixa mediano-longitudinal. Pontuações escurecidas distribuídas de forma abundante ao redor dos espiráculos. Cremaster terminal, alongado e escurecido, com ganchos simples de coloração castanhoclaros situados lateral e distalmente.

Mensurações: $(n=3)$. Comprimento médio da pupa em ambos os sexos: 21,2 mm. Duração mínima para a emergência dos adultos: 14 dias.

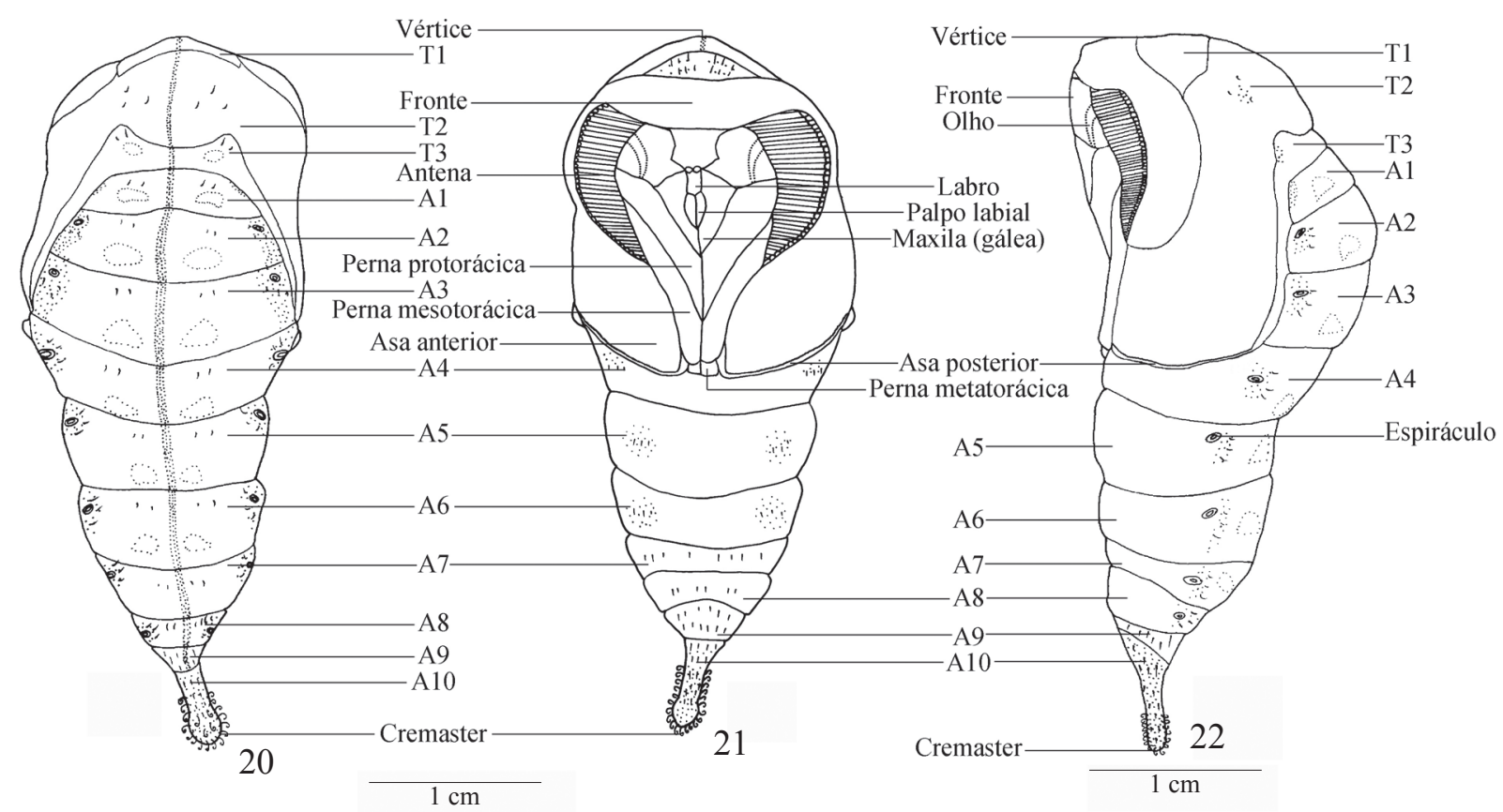

Figs. 20-22. Sarsina violascens. Pupa. 20, vista dorsal; 21, vista ventral; 22, vista lateral. 

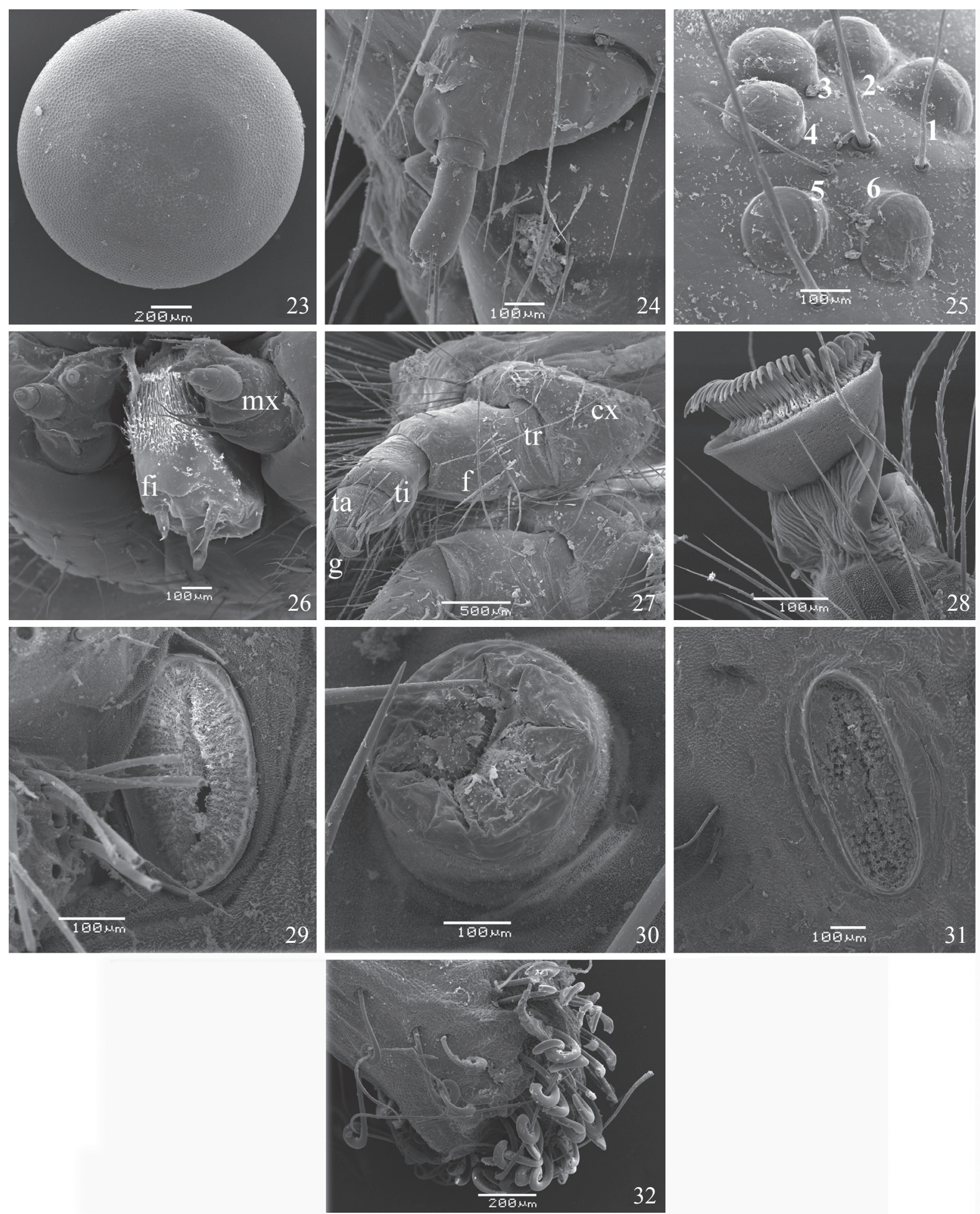

Figs. 23-32. Sarsina violascens. 23, ovo. 24-30. Larvas: 24-27. $6^{\circ}$ ínstar: 24, antena; 25, estemas; 26, fiandeira e maxilas; 27, perna protorácica. 28, $3^{\circ}$ ínstar perna do terceiro segmento abdominal. 29-30. $5^{\circ}$ ínstar: 29, espiráculo abdominal; 30, glândula mediano-dorsal do segmento A6. 31-32. Pupa: 31, espiráculo abdominal; 32, cremaster. $\mathrm{Cx}$ - coxa, $\mathrm{F}$ - fêmur, Fi - fiandeira, G - garra terminal, Mx - maxila, Ta - tarso, Ti - tíbia, $\mathrm{Tr}$ - trocânter.

\section{DISCUSSÃO}

Os hábitos observados em relação à alimentação de Sarsina violascens em Psidium cattleianum permitiram deduzir que a espécie não se apresenta como uma praga, ao passo que, em Eucalyptus spp. é considerada um dos principais desfolhadores, provocando sérios danos nos plantios (Zanuncio \& Lima 1975; Zanuncio et al. 1989; Zanuncio et al. 1992; Zanuncio et al. 1994; Viana \& Costa 2001; Bittencourt et al. 2003).

Características observadas neste estudo como a coloração e o tamanho do ovo, apresentam similaridade às obtidas por 
Zanuncio et al. (1992) com a mesma espécie. Entretanto em relação à duração do estágio de ovo, constatou-se aqui um tempo maior do que o observado pelos autores citados cuja eclosão se deu em 11 dias contra os 13 aqui obtidos.

O número de ínstares larvais e a duração dos mesmos aqui apresentados, corroboram os dados obtidos por Zanuncio et al. (1992), porém em nosso estudo, as larvas apresentaram comprimento superior em todos os ínstares. Tamanho e duração na fase de pupa foram também superiores no presente estudo. Estudos mais aprofundados poderão ser desenvolvidos para um maior esclarecimento destas variações, considerando que a localidade e o tipo de alimentação em ambos os experimentos foram diferentes.

Alguns caracteres diferenciam os indivíduos deste estudo de Sarsina purpurascens Walker, 1855 da Costa Rica, outra espécie do gênero com imaturos conhecidos e ilustrados em Chacón \& Montero (2007). Os ovos de Sarsina purpurascens são brancos com micrópila escurecida, as glândulas distribuídas dorso-medianamente nestas larvas são de coloração branca com pequena mancha rosa arredondada no pólo superior e presentes somente nos segmentos A6 e $\mathrm{A} 7$, as larvas apresentam ainda um número maior de cerdas distribuídas ao longo do corpo.

Nolinae e Arctiinae, subfamílias próximas filogeneticamente de Lymantriinae (Lafontaine \& Fibiger 2006), apresentam cerdas secundárias reunidas em tufos ou dispersas sobre verrugas (Stehr 1987; Scoble 1992). S. violascens assim como as espécies de Nolinae e Arctiinae possui cerdas secundárias sobre verrugas, compartilhando com Arctiinae a pilosidade densa e longas cerdas com projeções como farpas.

Na literatura, a presença de glândulas circulares dorsomedianas são indicadas somente nos segmentos A6 e A7 para Lymantriinae (Stehr 1987; Scoble 1992; Kitching \& Rawlins 1998) característica essa que os mesmos autores consideram como sinapomorfia para a subfamília.

Agradecimentos. Ao Centro de Microscopia Eletrônica, ao Táxon-line da Universidade Federal do Paraná (UFPR) pelas fotografias, a CAPES e ao $\mathrm{CNPq}$ e, aos revisores anônimos pelas sugestões e atenção dispensadas à revisão do artigo.

\section{REFERÊNCIAS}

Bittencourt, M. A. L.; L. Boaretto; I. Serafim \& E. Berti Filho. 2003. Fauna de Lepidoptera associada a um ecossistema natural no estado de São Paulo. Arquivos Instituto Biológico 70: 85-87.

Borror, D. J. \& D. M. Delong. 1971. Introdução ao Estudo dos Insetos. Rio de Janeiro, USAID \& Edgar Blucher Ltda, 654 p.
Chacón I. \& J. Montero. 2007. Mariposas de Costa Rica/ Butterflies and Moths of Costa Rica. Costa Rica, Editorial INBio, 624 p.

Costa, J. T. 2006. The Other Insect Societies. Cambridge, Mass. Belknap/ Harvard University Press, 812 p.

Dias, M. M. 2006. Lepidoptera, p. 175-204. In: C. Costa; S. Ide; C. E. Simonka. (Org.). Insetos Imaturos. Metamorfose e Identificação. São Paulo, Holos, 249 p.

Kitching, I. J. \& J. E. Rawlins. 1998. The Noctuoidea. In: N. P. Kristensen (ed.) Lepidoptera, Moths and Butterflies Vol. 1: Evolution, Systematics and Biogeography. p. 355-401. Handbook of Zoology IV /35. Berlin and New York, Walter de Gruyter, $487 \mathrm{p}$.

Lafontaine, J. D. \& M. Fibiger. 2006. Revised higher classification of the Noctuoidea (Lepidoptera). Canadian Entomology 138: 610-635.

Marques, M. C. M.; J. H. Pedrosa- Macedo \& C. W. Smith. 2007. Fenologia do Araçazeiro no Primeiro Planalto do Estado do Paraná, p. 47-53. In: J. H. Pedrosa- Macedo; A. Dalmolin \& C. W. Smith (Orgs.). O Araçazeiro: Ecologia e Controle Biológico. Curitiba, FUPEF, 232 p.

Mosher, E. 1916. A classification of the Lepidoptera based on characters of the pupa. Bulletin of the Illinois State Laboratory of Natural History 12: $1-165$.

Peterson, A. 1962. . Larvae of Insects. An Introduction to Nearctic Species. Part I Lepidoptera and Plant Infesting Hymenoptera. Ann Arbor, Edwards Brothers Inc., 315 p.

Rougerie, R. \& Y. Estradel. 2008. Morphology of the preimaginal stages of the African emperor moth Bunaeopsis licharbas (Maassen and Weyding): phylogenetically informative characters within the Saturniinae (Lepidoptera: Saturniidae). Journal of Morphology 269: 207-232.

Scoble, M. J. 1992. The Lepidoptera: form, function and diversity. London, Oxford University Press \& Natural History Museum, 404 p.

Souza, L. P. \& M. D. G. Sobral. 2007. Morfotipos do Araçazeiro, Psidium cattleianum Sabine (Myrtaceae) no Estado do Paraná, p. 19-28. In: J. H. Pedrosa- Macedo, A. Dalmolin \& C. W. Smith (Orgs.). O Araçazeiro:Ecologia e Controle Biológico. Curitiba, FUPEF, 232 p.

Stehr, F. W. 1987. Order Lepidoptera. p. 288-596 In: F. W. Stehr (ed.). Immature Insects. v.1, Duboque, Kendall Hunt, 754 p.

Viana, T. M. B. \& E. C. Costa. 2001. Lepidopterous associated with two forest communities in Itaara, RS. Ciência Florestal 11: 67-80.

Zanuncio, J. C. \& J. O. G. Lima. 1975. Ocorrências de Sarsina violascens (Herrich-Schaeffer, 1856) (Lepidoptera, Lymantriidae) em eucaliptos de Minas Gerais. Brasil Florestal 6: 48-50.

Zanuncio, J. C.; E. C. do Nascimento; F. R. A. Camargo \& T. V. Zanuncio. 1994. Fauna de Lepidoptera, associada à eucaliptocultura, nas regiões de Caçapava e São José dos Campos, São Paulo. Cerne 1: 78-94.

Zanuncio, J. C.; G. P. Santos; R. S. Saraiva \& T. V. Zanuncio. 1992. Ciclo de vida e consumo foliar de Sarsina violacens (Herrich-Schaeffer, 1856) (Lepidoptera, Lymantriidae), em Eucalyptus urophylla. Revista Brasileira de Entomologia 36: 843-850.

Zanuncio, J. C.; G. P. Santos; R. C. Sartório; N. dos Anjos \& L. C. C. Martins. 1989. Levantamento e flutuação populacional de lepidópteros associados à eucaliptocultura: 3- Região do Alto São Francisco, Minas Gerais, Março de 1988 a fevereiro de 1989. Instituto de Pesquisas e Estudos Florestais 41-42: 77-82.

Zenker, M. M.; I. S. Lima; A. Specht \& A. G. Duarte. 2007. Caracterização morfológica dos imaturos de Hyponeuma taltula (Schaus) (Lepidoptera, Noctuidae, Herminiinae). Revista Brasileira de Zoologia 24: 11011107.

Wikler, C. \& M. D. Vitorino. 2007. Entomofauna Associada ao Araçazeiro no Estado do Paraná, p. 93-98. In: J. H. Pedrosa- Macedo, A. Dalmolin \& C. W. Smith (Orgs.). O Araçazeiro: Ecologia e Controle Biológico. Curitiba, FUPEF, 232 p. 